\title{
Remote sensing observation used in offshore wind energy
}

Hasager, Charlotte Bay; Pena Diaz, Alfredo; Christiansen, Merete Bruun; Astrup, Poul; Nielsen, Niels Morten; Monaldo, F.; Thompson, D.; Nielsen, P.

Published in:

I E E E Journal of Selected Topics in Applied Earth Observations and Remote Sensing

Link to article, DOI:

10.1109/JSTARS.2008.2002218

Publication date:

2008

Document Version

Publisher's PDF, also known as Version of record

Link back to DTU Orbit

Citation (APA):

Hasager, C. B., Pena Diaz, A., Christiansen, M. B., Astrup, P., Nielsen, N. M., Monaldo, F., Thompson, D., \& Nielsen, $P$. (2008). Remote sensing observation used in offshore wind energy. I E E Journal of Selected Topics in Applied Earth Observations and Remote Sensing, 1(1), 67-79.

https://doi.org/10.1109/JSTARS.2008.2002218

\section{General rights}

Copyright and moral rights for the publications made accessible in the public portal are retained by the authors and/or other copyright owners and it is a condition of accessing publications that users recognise and abide by the legal requirements associated with these rights.

- Users may download and print one copy of any publication from the public portal for the purpose of private study or research.

- You may not further distribute the material or use it for any profit-making activity or commercial gain

- You may freely distribute the URL identifying the publication in the public portal 


\title{
Remote Sensing Observation Used in Offshore Wind Energy
}

\author{
Charlotte Bay Hasager, Alfredo Peña, Merete Bruun Christiansen, Poul Astrup, Morten Nielsen, Frank Monaldo, \\ Donald Thompson, and Per Nielsen
}

\begin{abstract}
Remote sensing observations used in offshore wind energy are described in three parts: ground-based techniques and applications, airborne techniques and applications, and satellite-based techniques and applications. Ground-based remote sensing of winds is relevant, in particular, for new large wind turbines where meteorological masts do not enable observations across the rotor-plane, i.e., at 100 to $200 \mathrm{~m}$ above ground level. Light detection and ranging (LiDAR) and sound detection and ranging (SoDAR) offer capabilities to observe winds at high heights. Airborne synthetic aperture radar (SAR) used for ocean wind mapping provides the basis for detailed offshore wind farm wake studies and is highly useful for development of new wind retrieval algorithms from $\mathrm{C}$-, L-, and X-band data. Satellite observations from SAR and scatterometer are used in offshore wind resource estimation. SAR has the advantage of covering the coastal zone where most offshore wind farms are located. The number of samples from scatterometer is relatively high and the scatterometer-based estimate on wind resources appears to agree well with coastal offshore meteorological observations in the North Sea. Finally, passive microwave ocean winds have been used to index the potential offshore wind power production, and the results compare well with observed power production (mainly land-based) covering nearly two decades for the Danish area.
\end{abstract}

Index Terms-Light detection and ranging (LiDAR), offshore, remote sensing, scatterometer, sound detection and ranging (SoDAR), synthetic aperture radar (SAR), wind energy.

\section{INTRODUCTION}

$\mathbf{T}$ HE history of offshore wind farming dates 15 years back. The first offshore wind farm was installed in Denmark in 1992. This is the Vindeby wind farm with 11 wind turbines of $450 \mathrm{~kW}$ each placed in two parallel rows. Since then a dramatic growth in the offshore wind farm capacity has taken place in

Manuscript received September 19, 2007; revised January 8, 2008. Current version published October 15, 2008. This work was supported in part by the Danish Research Academy for the project SAT-WIND Sagsnr. 2058-03-0006 and Sagsnr. 2104-05-0084, in part by the the Danish Council for Strategic Research to the project $12 \mathrm{MW}$ Sagsnr. 2104-05-0013, and in part by the ESA EOMD project EO-windfarm 17736/03/I-IW.

C. B. Hasager, A. Peña, M. B. Christiansen, P. Astrup, and M. Nielsen are with Ris $\varnothing$ National Laboratory for Sustainable Energy, DTU, Roskilde, Denmark (e-mail: charlotte.hasager@risoe.dk; alfredo.pena. diaz@risoe.dk; merete.bruun.christiansen@risoe.dk; poul.astrup@risoe.dk; morten.nielsen@risoe.dk).

F. Monaldo and D. Thompson are with the Johns Hopkins University, Applied Physics Laboratory, Laurel, MD 20723 USA (e-mail: frank.monaldo@jhuapl. edu; donald.r.thompson@jhuapl.edu).

P. Nielsen is with EMD International A/S, Aalborg, Denmark (e-mail: pn@emd.dk).

Color versions of one or more of the figures in this paper are available at http://ieeexplore.ieee.org.

Digital Object Identifier 10.1109/JSTARS.2008.2002218
Denmark. In the years 1997-2004, the growth rate was $71 \%$ (http://www.ec.europa.eu/energy/energy_policy/facts_en.htm). Currently, ten offshore wind farms are in operation in Denmark among those the two largest wind farms in the world, the Horns Rev wind farm in the North Sea with $802 \mathrm{MW}$ turbines and the Nysted wind farm in the Baltic Sea with 72 2.3 MW turbines. The experience in offshore wind farming in Denmark has led to sincere interest in wind energy in Europe and worldwide.

The expectations of the European Wind Energy Association (EWEA $2007 \mathrm{http}: / / \mathrm{www} . e w e a . o r g$ ) are that 50\% of the installed wind power capacity in Europe will be offshore in year 2030 totaling $150 \mathrm{GW}$ offshore. This number may be compared with the global offshore capacity of $1 \mathrm{GW}$ and land-based capacity of $74 \mathrm{GW}$ in the year 2006. The global growth rate of wind power capacity was $25 \%$ in the years 2000 to 2005 and this trend is expected to continue. With the EU target of $20 \%$ renewable energy by year 2020 wind energy will contribute a significant share.

The history in remote sensing observations on ocean winds happened much in parallel to development of offshore wind energy. For instance the European Space Agency (ESA) satellite ERS-1 equipped with a SAR and scatterometer was launched in year 1991 for research. Algorithms were developed for ocean wind mapping based on these types of remote sensing data. SAR and scatterometer observations have been collected continuously since then. A few years earlier-in 1987-the first satellite-borne passive microwave (SSM/I) instrument was flown for the specific purpose of mapping ocean winds and the SSM/I satellites have delivered a continuous ocean wind speed time series since. Already one decade earlier, however, the SeaSAT satellite operated three months in space and successfully demonstrated ocean wind mapping from SAR, scatterometer, and passive microwave.

Ground-based remote sensing instruments and airborne remote sensors have been developed during the same years with the SoDAR technique dating back to the 1960s but with a recent revival, e.g., the Triton SoDAR [34] and the AQSystems SoDAR (http://www.aqs.se) among others. LiDAR such as Zephir (http://www.qinetiq.com/home/commercial/energy/ZephIR.html) and WindCube (http://www.leosphere.com/) were developed in the new millennium with the specific goal of providing wind data at different levels in the atmosphere. A wind LiDAR will be flown on the ESA ADM-Aeolus mission with scheduled launch in 2009.

Challenges of observing offshore winds are cost, access, reliability, and accuracy. It is costly to install and maintain offshore meteorological masts. The height of wind turbines has increased by around $5 \mathrm{~m}$ per year since 1990. In year 2006 around $80 \%$ of 


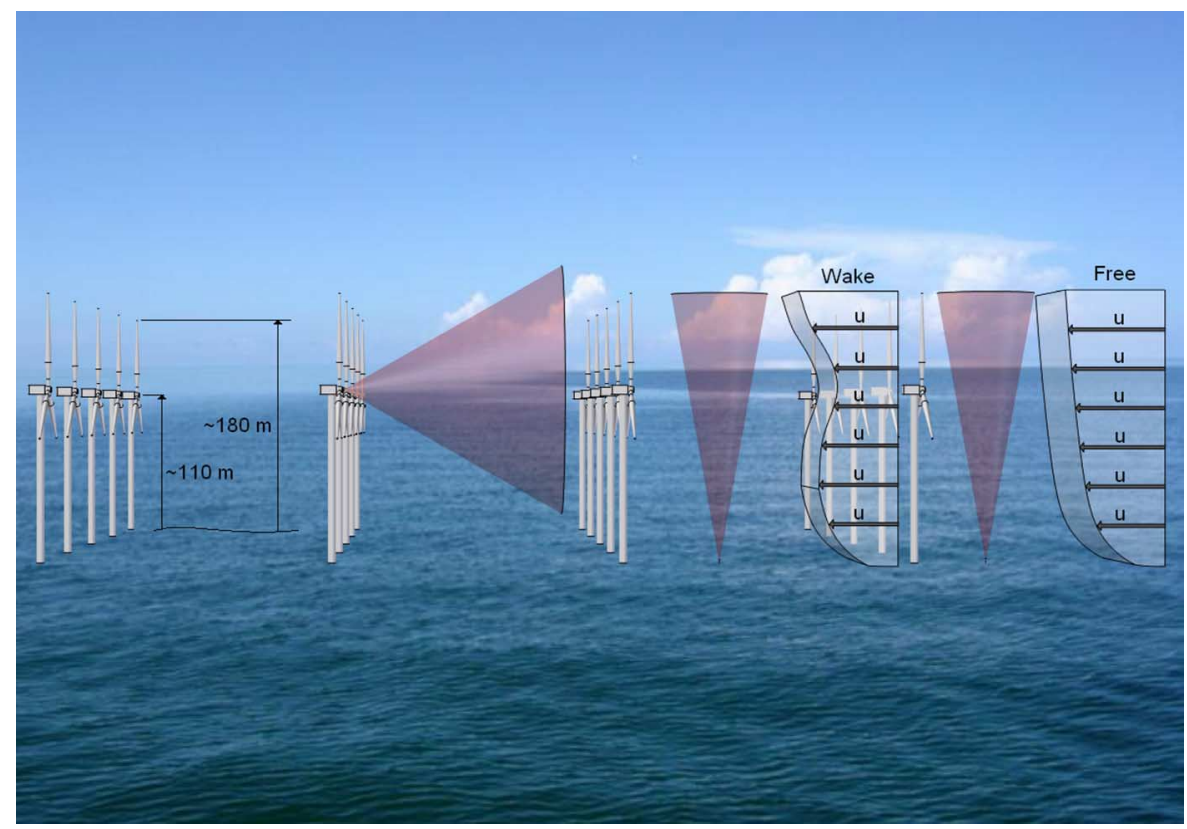

Fig. 1. Different configurations in observations used in the wind industry based on ground-based remote sensing techniques. At the far left is indicated approximate dimensions of wind turbine; in the middle the observation cones of LiDAR mounted on the hub or nacelle and on the ground; to the right is shown the wake influenced vertical wind profile and to the far right the undisturbed vertical wind profile.

the newly installed wind power consists of large wind turbines between 1 and 2.5 MW turbines [38]. These large wind turbines operate at 100 to $200 \mathrm{~m}$ and, therefore, the wind climate at these very high levels in the atmosphere needs to be quantified. Thus, very tall masts are needed but are not really feasible to install and operate. Therefore, ground-based remote sensing and profiling methods of winds from above are very attractive new solutions for quantification of winds relevant in wind energy.

This paper presents recent achievements based on groundbased, airborne and satellite remote sensing techniques for the purposes of wind resource estimation, wind profiling, wake effects, and wind-indexing for offshore wind energy.

\section{GROUND-BASED REMOTE SENSING: LIDAR AND SoDAR}

The rapid expansion of wind energy in the last decades has been followed by the investigation and adaptation of different remote sensing techniques for the assessment of the wind resource. The ground-based remote sensing techniques are part of those technologies which are used to observe wind characteristics. Most frequently applied in the wind industry are sound detection and ranging (SoDAR) and light detection and ranging (LiDAR).

\section{A. Technology}

Both SoDAR and LiDAR are based on the Doppler-shift principle. The SoDAR transmits acoustic pulses into the atmosphere and receives reflections from the atmospheric sound scattering. Part of the transmitted sound pulses is reflected back towards the instrument's sound detectors due to temperature fluctuations in the different layers of the atmosphere. These variations in temperature are caused by thermally induced turbulence [1], [12]. In the case of the LiDAR instruments, it is a beam of light which is sent into the atmosphere [35]. The aerosols and particles in the different air layers reflect back the signal towards the instrument's light detectors. Both instruments compare the Doppler-shifted frequency between the original and the reflected signal. This frequency is transformed to a line-of-sight velocity, the magnitude of the wind velocity along the beam direction. Thus, if the light or sound is sent at different angles relative to the zenith, the line-of-sight velocity can be decomposed into the three wind speed components using the geometry of the scanning configuration.

The ability of the SoDAR and LiDAR instruments to perform measurements of wind speed in different layers of the atmosphere has attracted the attention of the wind energy industry. This is due basically to the different limitations that the standard sensing techniques like cup and sonic anemometers are now facing in this growing field. Cup and sonic anemometers measure accurately the wind speed but they need to be mounted on structures. This is a limiting factor when the assessment is performed at heights around $50 \mathrm{~m}$ or higher up due to the cost of such arrangement. The installed turbines have already exceeded this range of heights. Nowadays, the hubs of the biggest turbines are around $110 \mathrm{~m}$; thus, they are reaching levels up to $180 \mathrm{~m}$ at the highest tip blade point (Fig. 1).

The vertical observational limit of the SoDARs and LiDARs has been increased in the last decade. The commercial units used in wind energy can observe winds at heights $\sim 200 \mathrm{~m}$, but this limit depends on the continuous improvement of the optical and sound transmitting/receiving systems [1].

\section{B. Offshore Application}

One of the attractive application areas of wind energy is offshore. Although it is well known that the wind speeds are higher and turbulence levels are lower over water, detailed knowledge of the offshore wind resource in regard to large wind turbines is 

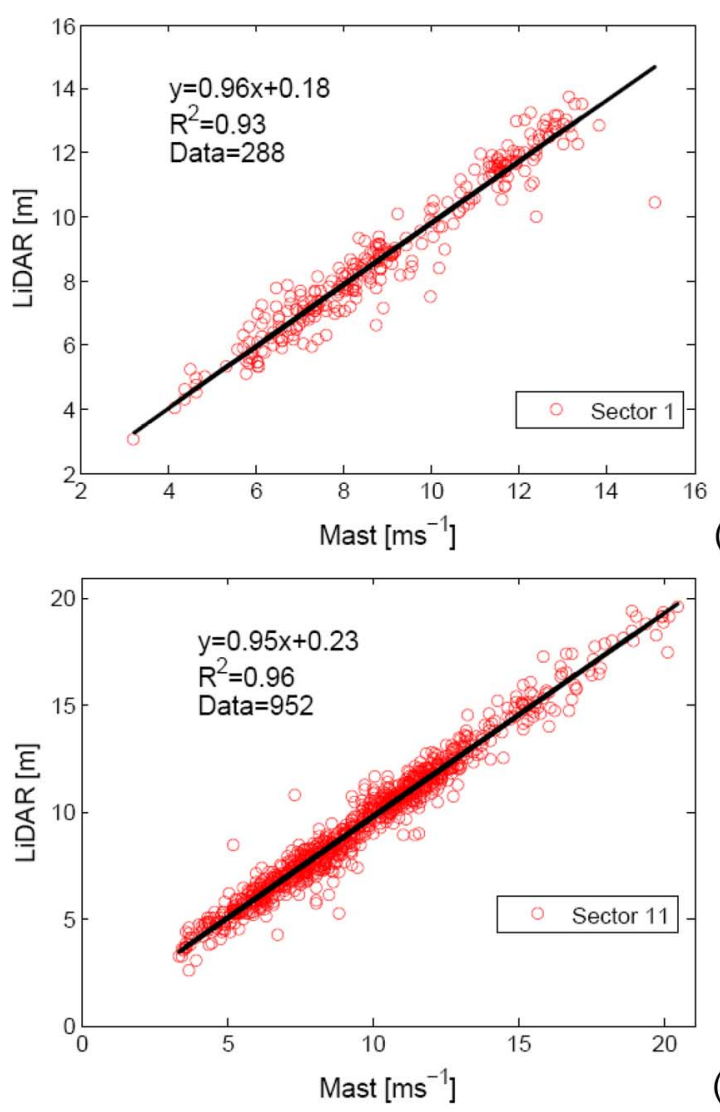

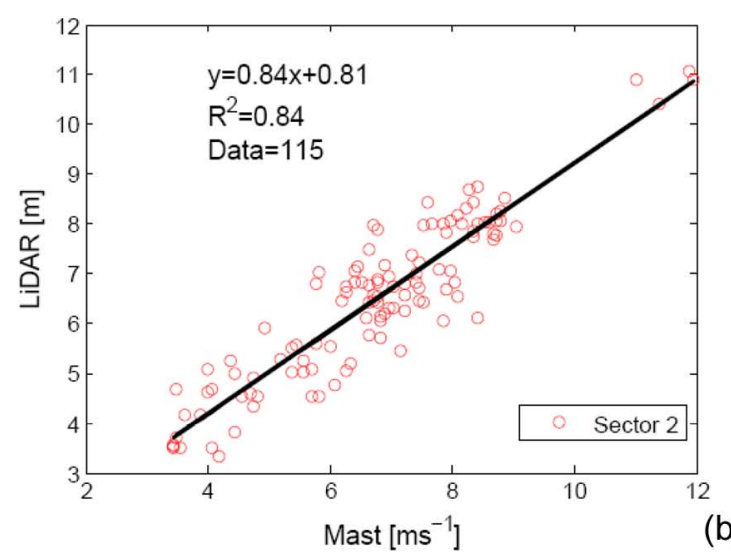

(b)

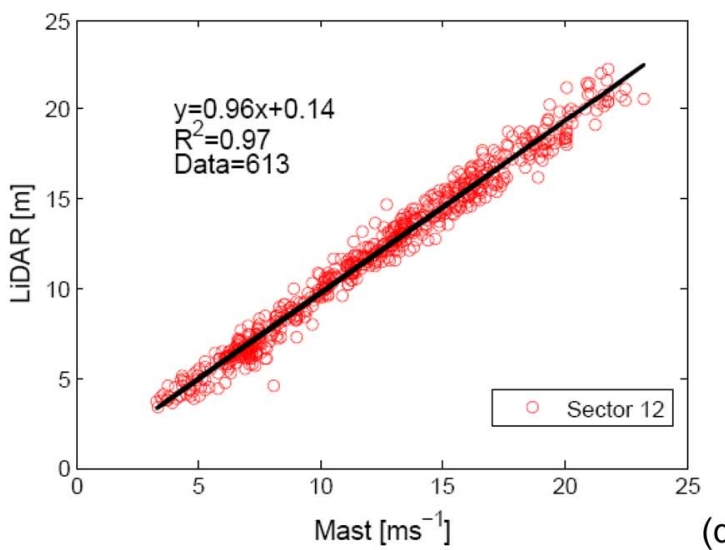

Fig. 2. Comparison of horizontal mean wind speeds observed from LiDAR at $63 \mathrm{~m}$ with cup anemometer measurements at $62 \mathrm{~m}$ AMSL in four $30^{\circ}$ sectors in the period May 3, 2006 to October 24, 2006. Data less than $2 \mathrm{~ms}^{-1}$ are not included as well as rainy days.

immature. The standard sensing techniques are particularly expensive to install at these locations. The ability of LiDARs and SoDARs to perform wind profiling can be used to estimate the offshore wind resource.

The instruments can be installed at low platforms or be transported by ships to observe winds. The LiDAR also can be installed on the turbine's nacelle where it is able to scan in an upwind or downwind configuration (Fig. 1). In this way, not only the free atmospheric wind is studied but also the wake induced by the turbine or the wind farm. This is important for wind turbine manufactures due to the different types of loads which are enlarged by wake effects and wind/wake profiles on the turbine's elements.

The new remote sensing techniques provide the advantage of mobility. They are continuously improved to be easy-portable. In this form, they can be used to perform wind profiling over an entire wind farm moving the instrument(s) to various positions within and near a wind farm. The technologies hold potential for the future planning of wind farms and possibly will be introduced as a wind turbine standard element.

\section{Information From Ground-Based Remote Sensing}

Examples of observations from LiDAR are shown in Figs. 2 and 3. In the first figure, the 10-min horizontal mean wind speeds from LiDAR are compared with cup anemometer data. The cup anemometer was placed on a meteorological mast at 62-m above mean sea level (AMSL). The ZephIR's wind

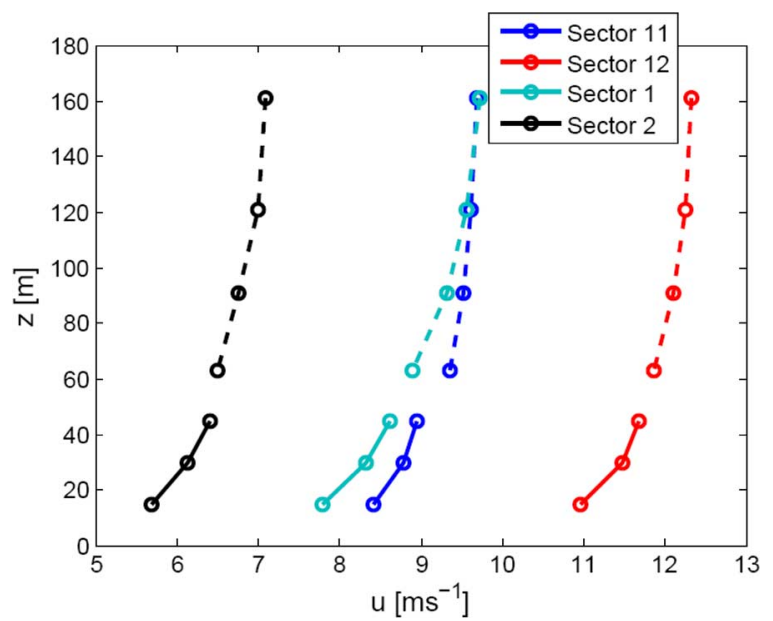

Fig. 3. Horizontal mean wind speed profiles for three cup anemometers on Mast 2 and LiDAR measurements at the Horns Rev platform. The open circles indicate the observational heights.

LiDAR was placed on the transformer/platform of the Horns Rev offshore wind farm at $20 \mathrm{~m}$ AMSL and observed winds at $63,91,121$, and $161 \mathrm{~m}$ AMSL. Due to the high homogeneity of the site the cup anemometer and LiDAR measurements compare very well, although the mast and platform were separated $5.6 \mathrm{~km}$ apart at $282^{\circ}\left(0^{\circ}\right.$ indicates the north and the angle is measured clockwise). The mast observes winds few kilometers upwind when the wind comes from the dominant direction, i.e., 
the westerly sectors (sector 11: $285-315^{\circ}$ ). Most available data are from this sector [31] and much less from sectors 1 and 2.

The comparison is good with high correlation coefficients and slopes near unity for the sectors where the wind direction is parallel to the angle between both mast and platform structure. In the sectors 11 and 12 high wind speeds are observed as the atmospheric flow is from the open sea sector. The airmass is first observed at the mast then around $5 \mathrm{~km}$ downstream observed by the LIDAR.

The correlation and slope are lower for sector 1 and 2 due to the influence of land in this direction. Jutland in Denmark is located approximately $20 \mathrm{~km}$ east of the mast and platform. In the sectors 1 and 2 lower wind speeds are observed as the atmospheric flow is from the land sector. The airmasses observed at the mast and platform are slightly different due to the experiment configuration. Furthermore the distance to land (fetch) are also slightly different. Therefore, the correlation coefficients are lower than for sectors 11 and 12 .

The other sectors are not shown because they are affected by the wind farm wake. Further information on the experiment is available in [17] and [31].

Horizontal mean wind speed profiles are shown in Fig. 3 observed from cup anemometer on the same mast at 15, 30, and $45 \mathrm{~m}$ AMSL within the four sectors $(1,2,11$, and 12). The cup anemometer observations at $62 \mathrm{~m}$ are left out because this instrument was installed differently from the other three instruments (top-pole mounted versus boom-mounted). The profiles of horizontal mean wind speed observed by the LiDAR at four heights are also shown in the figure for the same sectors.

It is noticed that the LiDAR wind profiles follow the wind observations at the mast. In this way, the LiDAR adds information which is hard to study with standard instruments due to the limitation of the height of masts. Part of the differences between the LiDAR and the mast wind profiles may be related to flow distortion effects due to the mast structure on the cup anemometers. The LiDAR does not face this type of distortion problems. Therefore, LiDAR is recommended for the study of wind profiles over homogenous terrain.

\section{Discussion}

The ground-based remote sensing techniques also face some disadvantages. Although the cost of both SoDAR and LiDAR units has been decremented in the last years, this is not comparable to the cost of a single cup or sonic anemometer. Another problem is related with the nature of the volume measurement. Over inhomogeneous terrain, the effects of wind distortion over obstacles may attenuate the observation as the measurements are taken inside a large effective volume.

In the specific case of the SoDAR, the instrument presents also some drawbacks. The most important one is the SODAR's dependency on temperature variation in the atmosphere. This, in principle, reduces the measurements taken under neutral atmospheres which are attractive conditions for wind energy due to the high wind speed and relative lower turbulence levels. Indeed, at very high wind speeds (above $\sim 15 \mathrm{~ms}^{-1}$ ) [12], the signal to noise ratio is decreased considerably due to the background noise, and the amount of data is reduced. The background noise may include ambient noise or fixed echoes from surrounding objects. Due to the dependency of the SoDAR measurements on the site conditions, it is always recommended to re-calibrate the system with a meteorological tower before the wind resource assessment is performed.

The LiDAR is more costly than the SoDAR. LiDAR's optical parts are sensitive to misalignments and these lead to errors in the focus system. Nonuniform backscatter in the effective measurement volume is a serious problem which is amplified by the presence of low clouds or low aerosol content at the focus height.

The logarithmic wind profile can be applied to predict winds in the surface layer but it is not valid for heights above this layer [11]. Thus, for shallow marine boundary layer, other scalings, e.g., the boundary-layer height scale, are needed. The aerosol profile observed by ceilometer indicates the limits where the boundary layer height is present, and this is an important scale parameter for the modeling of winds at higher levels in the atmosphere (beyond the lower $10 \%$ of the boundary layer, i.e., the surface layer).

A ceilometer is a variation of the LiDAR instrument. It sends short pulses of light into the atmosphere and measures the time delay between the original and the detected signal. This time delay is related to the height where the signal was backscattered. The so-called LiDAR equation (the instantaneous received power) is used in combination with the time delay to estimate the backscatter coefficient. The last is proportional to the amount of aerosols in the different layers in the atmosphere.

\section{AIRBORNE SAR}

Airborne SAR observations from the E-SAR (http://www.op. dlr.de/ne-hf/projects/ESAR/esar_englisch.html) from DLR, the German Aerospace Centre, have been collected near the Horns Rev wind farm during one day in October 2003. SAR data are collected from microwave radiation transmitted and received in certain wavelength and polarizations. C-band is $\sim 5.3 \mathrm{~cm}$ and L-band $\sim 21 \mathrm{~cm}$. The polarization of transmitted radiation is either horizontal $(\mathrm{H})$ or vertical $(\mathrm{V})$ and similar for receive $(\mathrm{H})$ or (V) for co-polarized data. The observations included $\mathrm{C}_{\mathrm{HH}}$, $\mathrm{C}_{\mathrm{VV}}, \mathrm{L}_{\mathrm{HH}}$, and $\mathrm{L}_{\mathrm{VV}}$ data. Analysis of the C-band data showed an area of reduced wind speed downstream of the wind farm. The reduction in wind speed-the wake effect-was found to be of the order of $10 \%$ in the near-wake field as expected during a period where most of the 80 wind turbines were in operation [6].

The airborne SAR data revealed a patchy and variable wake downstream of the turbines. Fig. 4 shows the wind farm configuration and the position of the airborne track. The wind speed wake observed by $\mathrm{C}_{\mathrm{VV}}$ along a cross-wind track is shown in Fig. 5. The free stream wind was around $13.5 \mathrm{~ms}^{-1}$ in this track and the minimum wind speed around $10.5 \mathrm{~ms}^{-1}$. Only airborne SAR can map the fine spatial details in wind speed variations over sea.

The analysis was extended with satellite ERS-2 SAR observations that supported the findings of the study based on airborne SAR data. In addition, the satellite SAR wind maps revealed that the wake in certain instances extended more than $20-\mathrm{km}$ downstream of the wind farm. This finding is much longer than 


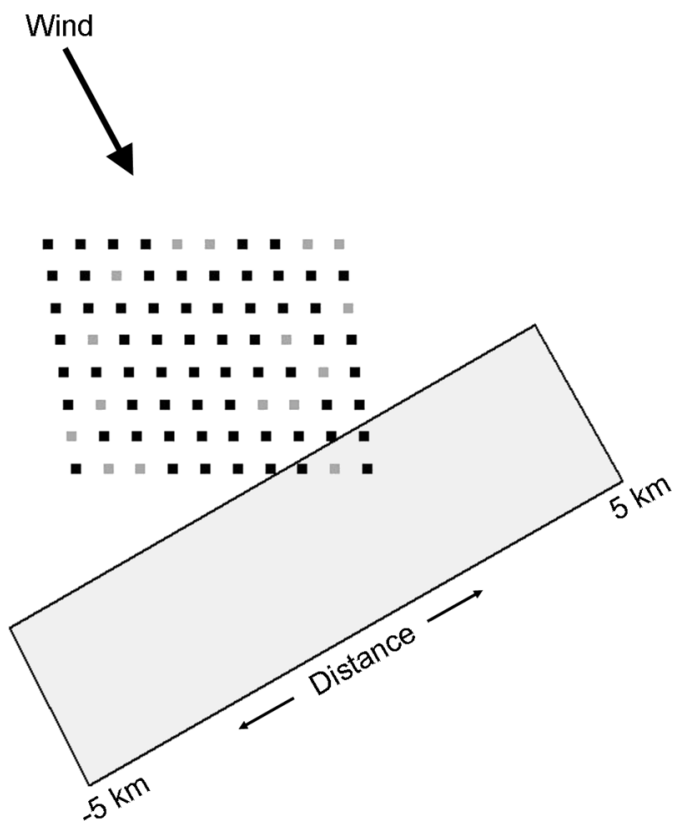

Fig. 4. Wind farm at Horns Rev with the operating wind turbines in black; the turbines out of service in grey at the time of the airborne SAR.

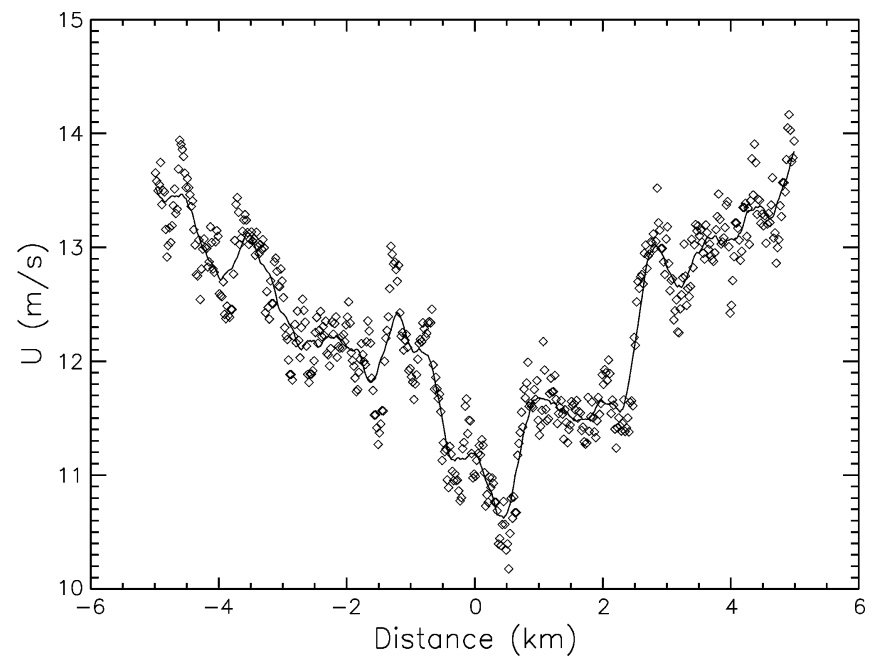

Fig. 5. Wind speed wake observed from airborne E-SAR CVV along the crosswind track with an average (running mean 20 box) line included.

current wake models prediction. Thus, the potential power production from wind farms in clusters may be more affected by wake than is generally assumed [5].

Airborne SAR data are highly useful in basic studies on polarization and ocean wind retrieval. The physics that governs microwave scattering from the ocean surface is only partly understood, and in particular, the following outstanding problem remains. The measured polarization ratios (HH/VV) of the backscattered cross section at moderate incidence angles for L-, C-, and X-band are larger than those predicted by the rough-surface scattering and surface spectral models commonly in use.

At $45^{\circ}$ incidence for example, the measured $\mathrm{HH} / \mathrm{VV}$ ratio for a $10 \mathrm{~ms}^{-1}$ wind directed toward the radar is about $-3 \mathrm{~dB}$ at X-band [22] and about $-5 \mathrm{~dB}$ or so at C-band [28]. This was found from data of a large offshore airborne SAR exper- iment. Based on an empirical approach they have calculated wind speed dependent values. For L-band data collected over the Horns Rev wind farm by the DLR E-SAR platform under similar wind conditions and radar geometry, it is found that the measured $\mathrm{HH} / \mathrm{VV}$ ratio is $\sim-4 \mathrm{~dB}$.

Simple Bragg-based scattering models predict the HH/VV ratio to be about $-9.5 \mathrm{~dB}$; independent on radar frequency. Ratios predicted by composite-type scattering models that include the effects of long-wave tilt and hydrodynamic modulation yield frequency dependence and a somewhat large ratio [33], but the predicted polarization ratios remain significantly smaller than the measurement data.

Airborne C- and L-band EMISAR data (http://www.oersted.dtu.dk/English/research/drc/rs/sensors/emisar.aspx) from the Technical University of Denmark covering the 16-km-long Great Belt Bridge in Denmark have been studied in order to test a new geophysical model function (GMF) for L-band SAR wind retrievals. Fig. 6 shows the L-band part of the EMISAR scene. Wind streaks and shadows from the land are visible and indicate a wind direction diagonal to the Great Belt bridge orientation.

Wind speeds were first retrieved from the C-band SAR data through inversion of the model function CMOD4 [36]. The wind speeds were then used to initiate forward runs of a new L-band GMF. Three preliminary versions of the GMF based on the spectral models of [2], [8], and [33] were tested. The predicted normalized radar cross sections (NRCS) were compared to the EMISAR L-band data (Fig. 7). The GMF using Elfouhaily's spectrum showed good agreement with the data at vertical polarization (V-pol) and was $\sim 2 \mathrm{~dB}$ lower at horizontal polarization (H-pol). GMFs using the Apel and Romeiser spectra were too high at $\mathrm{V}$-pol over the entire range of incident angles and also too high at $\mathrm{H}$-pol for angles $<40^{\circ}$ or so. Work is ongoing to further develop the L-band GMF. For example, it is necessary to account for the upwind/downwind asymmetry of NRCS.

Basic research as described above using airborne multifrequency polarimetric SAR is attracting much attention these years as currently five satellites are in orbit with different SAR sensors: RADARSAT-1, ERS-2, ENVISAT, ALOS, and TerraSAR-X.

\section{SATELLITE}

\section{A. Satellite SAR}

The Canadian RADARSAT-1 and the European ERS-1/2 and Envisat satellites all carry C-band SAR $(\sim 5.3 \mathrm{GHz})$. RADARSAT has HH-polarization, ERS-1/2 have VV-polarization and Envisat has VV- and $\mathrm{HH}$-polarization. In its alternating polarization mode the Envisat ASAR instrument is capable of transmitting vertically polarized radiation ( $\mathrm{V}$-pol) followed by horizontally polarized radiation (H-pol) on successive pulses, and collecting the reflected radiation in one of three distinct user-defined pairs: $\mathrm{HH}$ and $\mathrm{VV}, \mathrm{HH}$ and $\mathrm{HV}$, or $\mathrm{VV}$ and $\mathrm{VH}$. ERS-1/2 have been in orbit since 1991. RADARSAT-1 has been in orbit since 1995 and Envisat since 2002. Thus, the data archive spans 15 years. Ocean winds are being mapped routinely from RADARSAT and Envisat.

The Johns Hopkins University Applied Physics Laboratory (JHU/APL) has developed the APL/NOAA SAR Wind Retrieval System (ANSWRS). It is being used for near real-time 


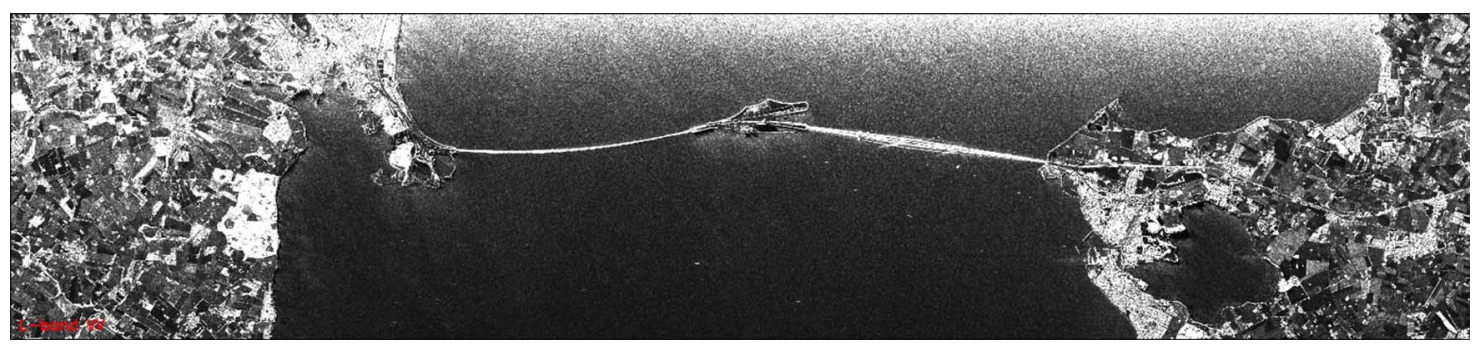

Fig. 6. EMISAR $\mathrm{L}_{\mathrm{VV}}$ from June 16, 1998 at 10.01 UTC showing the Great Belt Bridge (16 km long) between Funen and Zealand in Denmark. Courtesy: DRC DTU.

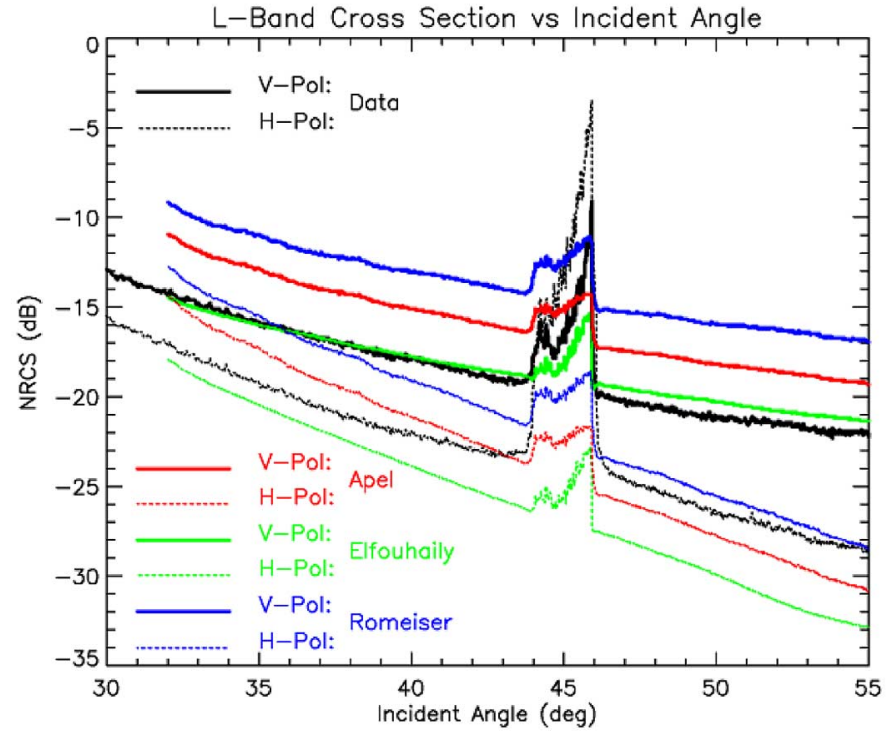

Fig. 7. L-band cross section versus radar incidence angle for the EMISAR scene in Fig. 4 and that predicted using three different spectral models.

wind field retrievals at NOAA, JHU/APL, and the Alaska SAR Facility (ASF). The ANSWRS software produces high-resolution wind speed fields with spatial resolution less than $1 \mathrm{~km}$. The algorithm is initialized using wind directions determined by the Navy Operational Global Atmospheric Prediction System (NOGAPS) models. An extensive database of SAR wind maps covering most areas of the globe are available at the web site: http://www.fermi.jhuapl.edu/sar/stormwatch/web_wind/. The wind maps are concentrated mainly in the Gulf of Alaska and coastal regions of continental U.S. and Europe. At Ris $\varnothing$ DTU, ANSWRS is also in operation with wind maps posted at web site: http://www.risoe.dk/business_relations/Products_Services/Software/VEA_windmaps.aspx. These results are based on Envisat images from the ESA EO project Scandia-SAR on offshore wind resources in the Scandinavian seas. Fig. 8 shows a wind map from the eastern part of the Baltic Sea from September 8, 2007 at 20.37 UTC. Near Copenhagen winds are from the northwest and a lee-effect along the east coast of the island Zealand and Sweden is seen using CMOD5 [18].

A great variety of interesting atmospheric conditions are mapped from the unique satellite SAR data sources. [4] provide insight to various atmospheric phenomena observed from SAR.

Wind direction may be determined directly from the SAR images. One method is the local gradient method algorithm for wind direction retrieval developed by [19], [21]. This method examines the change in intensity of the SAR image at various spatial scales. The method has been tested on a series of 91 ERS and Envisat SAR images covering the Horns Rev wind farm and the results gave standard deviation around $1.1 \mathrm{~ms}^{-1}$ and wind direction around $16^{\circ}$ compared to offshore meteorological observations collected at Horns Rev [7]. Earlier studies comparing offshore meteorological data and SAR winds have shown results of similar order of magnitude [14]-[16]. Comparison results between the estimated wind speeds from SAR-based maps using ANSWRS mainly covering the Gulf of Alaska and the U.S. East coast yielded agreement with buoy measurements to within $\pm 1.76 \mathrm{~m} / \mathrm{s} \mathrm{rms} \mathrm{[26]} \mathrm{and} \mathrm{with} \mathrm{QuikSCAT} \mathrm{wind} \mathrm{speeds}$ to within $\pm 1.25 \mathrm{~m} / \mathrm{s} \mathrm{rms} \mathrm{[24].} \mathrm{Comparisons} \mathrm{using} \mathrm{ship} \mathrm{data,}$ ocean buoy data, or meteorological model showed results of similar order of magnitude as described in other studies [20], [23], [25]. [40] demonstrated direct (manual, semi-automated) wind retrieval in SAR for improved wind mapping from SAR; thus, general improvement may be expected from this type of research. Other methods for mapping wind streaks in SAR images are fast Fourier transform (FFT) and wavelet analysis described by [9] and [10], respectively.

The Japanese ALOS PALSAR has a fully polarimetric transmit/receive capability at L-band $(\sim 1.2 \mathrm{GHz})$ and the German TerraSAR-X at X-band $(\sim 10 \mathrm{GHz})$. ALOS was launched in January 2006 and TerraSAR-X in June 2007. The ability to collect multipolarization satellite SAR images at three different frequencies (C-, L-, and X-band) represents a significant advance in satellite SAR acquisition technology. Similar refinement in the interpretation and processing of data from these new SAR sensors is required in order to fully utilize this new technology for remote-sensing applications. New ocean wind retrieval results are expected from the data as research is on-going. This is foreseen to advance offshore wind resource mapping in the future.

\section{B. On Wind Resource Mapping Using SAR}

Offshore wind farms such as Horns Rev in the North Sea and Nysted in the Baltic Sea cover areas $\sim 16$ to $25 \mathrm{~km}^{2}$, respectively. The Horns Rev wind farm is located from $14 \mathrm{~km}$ and further offshore and the Nysted wind farm is located from $9 \mathrm{~km}$ and further offshore; thus, it is of particular interest to map the coastal regions at or below 1-km-scale resolution and covering the coastal zone from 5 to $50 \mathrm{~km}$. Satellite SAR enables wind mapping at the relevant resolution covering the area of interest. This is of particular interest as the atmospheric flow in coastal 


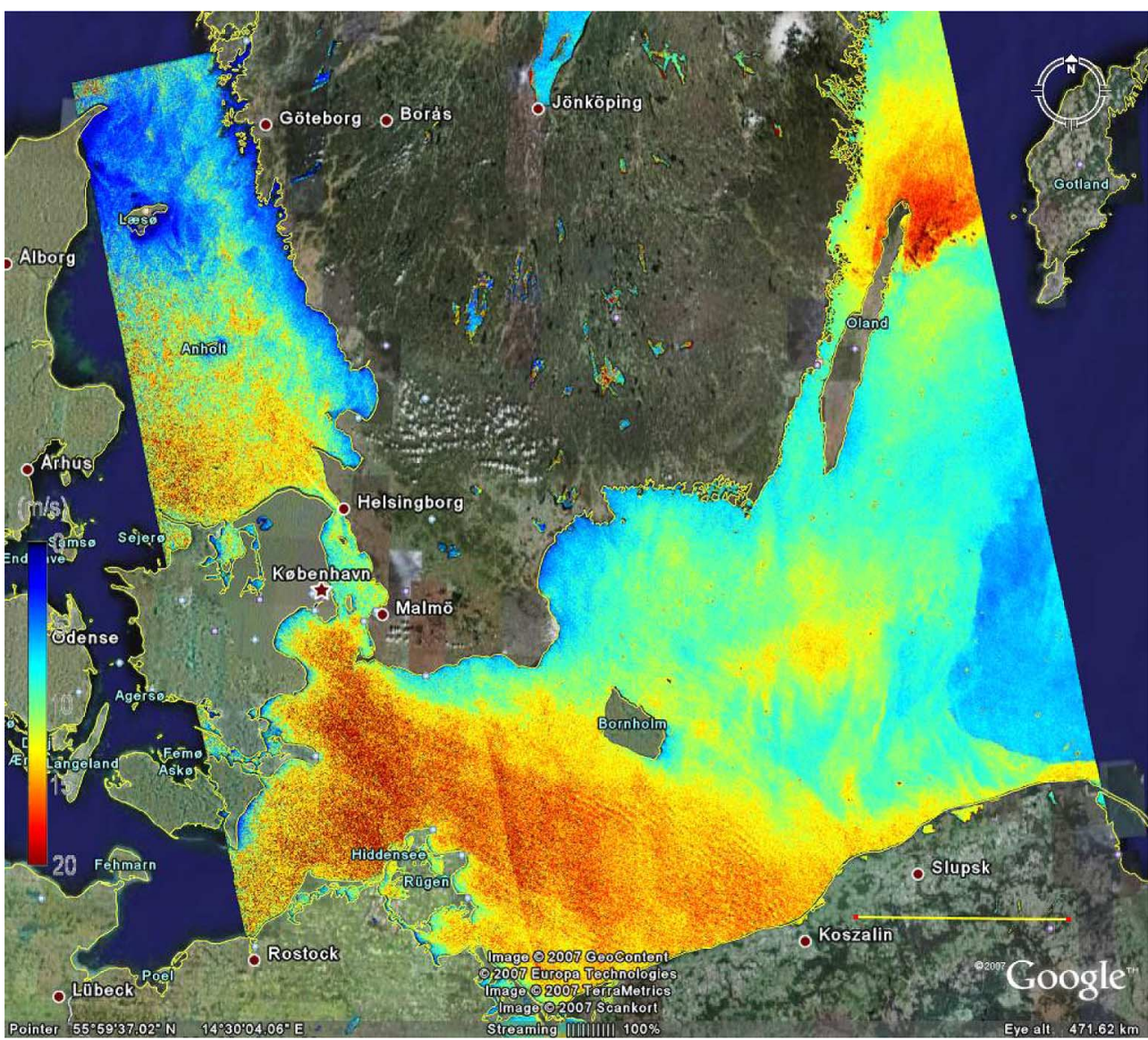

Fig. 8. Wind map of the Baltic Sea from Envisat on 8 September 2007 with northwesterly winds. The horizontal yellow line in the lower right is $100 \mathrm{~km}$. The legend on wind speed is from 0 (dark blue) to $20 \mathrm{~ms}^{-1}$ (dark red). Risø DTU/JHU-APL.

regions is often complex and not fully understood. Thus, SAR observations can provide estimates of the spatial variations in the coastal winds without any a priori knowledge. In contrast, atmospheric flow models need a priori information on, e.g., landscape features and obstacles.

The de facto method for wind resource mapping is based on the method originally developed in the European Wind Atlas [37] and available as software, the Wind Atlas Analysis and Applications Program (WAsP) [27], http://www.wasp.dk. A wind resource analysis is typically based on minimum one year of hourly wind speed and direction observations. In case the observations are collected at another height than that of the expected wind turbine hub-height, a wind profile calculation in the vertical is done in the software. For SAR and other satellite wind data, the level above sea is $10 \mathrm{~m}$; thus, extrapolation to higher levels is needed.

Software for wind resource estimation based on satellite SAR has been developed at Ris $\varnothing$. The newest software-SatelliteWAsP or S-WAsP-is based on input of SAR wind maps from ANSWRS. A series of SAR-based wind maps are used for calculating wind resource statistics. It has been important to investigate advantages and limitations of the method. The number of available SAR images is limited as a function of the relatively narrow swaths of SARs and the number of SARs in operation. A study on the number of samples and fixed overpass times by [3] and [32] showed that the mean wind speed can be determined with relatively good accuracy while, e.g, . energy density will be rather uncertain as many more samples are

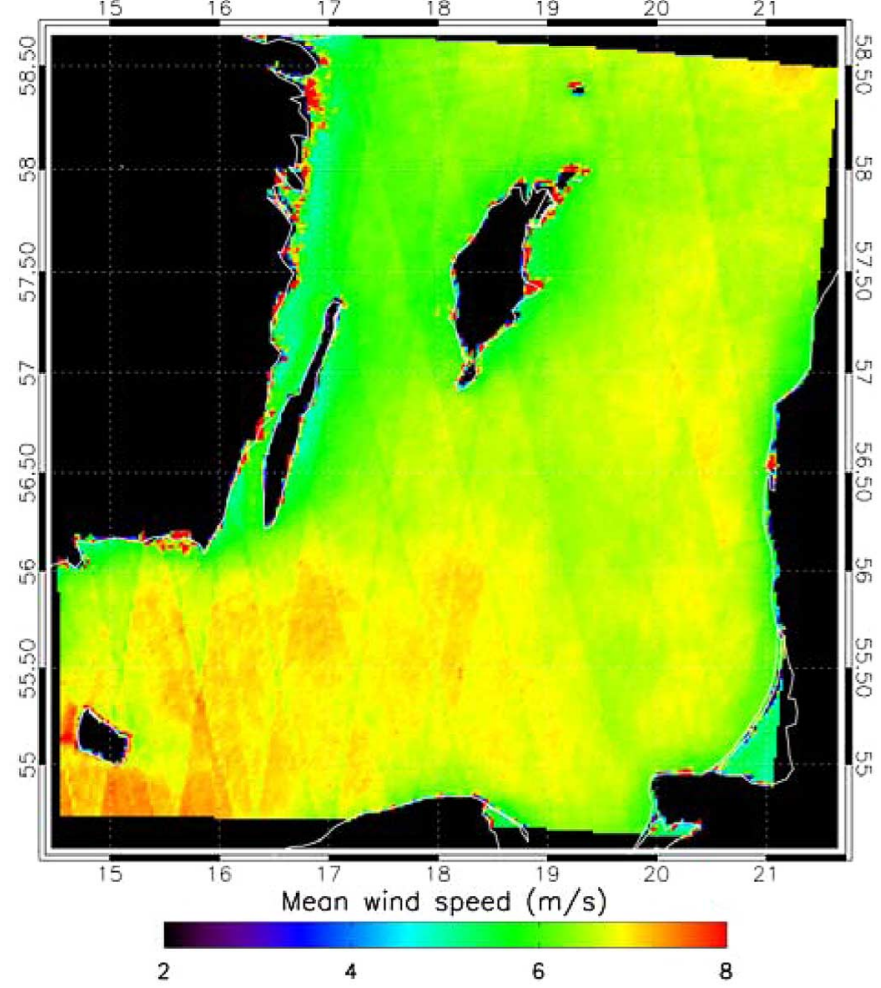

Fig. 9. Mean wind speed based on Envisat ASAR images covering the Baltic Sea. 


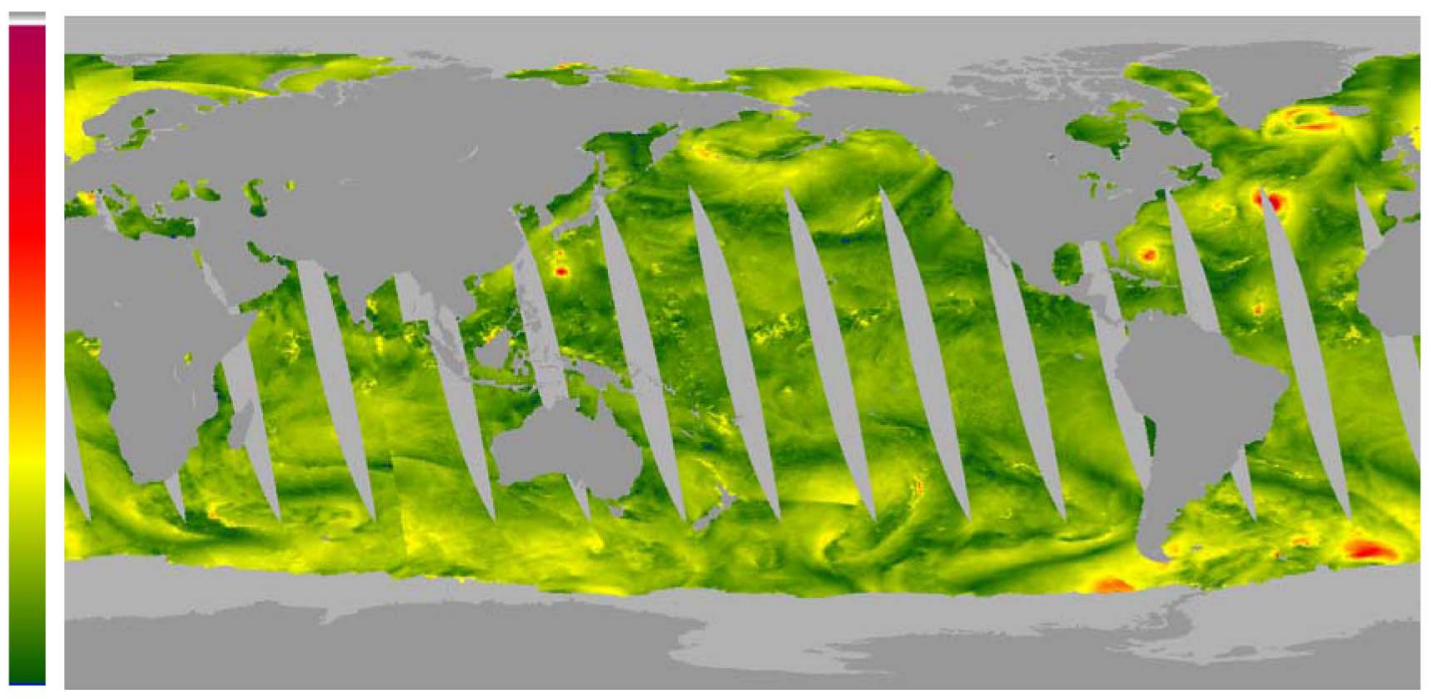

Fig. 10. QuikSCAT wind speed field of September 24, 2004 from the ascending passes. Colour scale is linear from $0 \mathrm{~ms}^{-1}$ (dark green) to $50 \mathrm{~ms}^{-1}$ (dark red). Dark grey is land mass and light grey is missing data.

needed to provide a reliable estimate. Thus, it was concluded that SAR-based wind resource estimation will have a quality relevant in prefeasibility studies only. SAR-based wind resource maps may be used as guide to site an offshore meteorological mast or ground-based remote sensing instruments. In case a reliable estimate on the wind resource is already available within the coastal area, SAR-based wind resource statistics may help to identify wind resource variations within the region.

The nature of SAR-based wind maps prompted a need for development of spatial averaging, filtering and Weibull statistics on the SAR-based wind maps; [13] and [30] described the technical details where most importantly the grid cells upwind of the point of interest (any point in the selected domain) are averaged by footprint-weighted function. The few samples available within each wind direction sector (bin) are used to calculate the Weibull shape and scale parameters, and in particular, the fact that SAR-based wind mapping exclude winds below a certain threshold $\left(<2 \mathrm{~ms}^{-1}\right)$ and above a certain threshold $\left(>24 \mathrm{~ms}^{-1}\right.$ or more) made the choice of the maximum likelihood estimator relevant for Weibull fitting to SAR-based wind data. SAR-based wind resource estimates are provided as maps, wind roses, statistical reports and as output (tab-file) compatible with WAsP. [7] used the software for a study based on $~ 100$ SAR images at the Horns Rev wind farm. The major results were standard deviation in wind speed $\sim 1.1 \mathrm{~ms}^{-1}$ using wind direction from the mast and $\sim 1.3 \mathrm{~ms}^{-1}$ using wind direction from the gradient method. The mean wind speed observed from 91 in situ data was $7.6 \mathrm{~ms}^{-1}$, from $91 \mathrm{SAR}$ wind maps $7.3 \mathrm{~ms}^{-1}$ and from the Horns Rev Lightship from 1962-80 $7.3 \mathrm{~ms}^{-1}$ [37].

Using 239 Envisat ASAR wide-swath-mode scenes covering the Baltic Sea, the mean wind speed map is calculated and shown in Fig. 9. It is based on more than 100 wind maps in most of the domain (except near island Bornholm down to around 80 wind maps). East of island Gotland at $57^{\circ} \mathrm{N}, 19.5^{\circ} \mathrm{E}$ the mean wind speed from 188 samples is $6.6 \mathrm{~ms}^{-1}$, south of Gotland at $56.7^{\circ} \mathrm{N}, 18.0^{\circ} \mathrm{E}$ the mean wind speed from 173 samples is $6.5 \mathrm{~ms}^{-1}$ and at $55.0^{\circ} \mathrm{N}, 20.0^{\circ} \mathrm{E}$ near Russia the mean wind speed is $6.3 \mathrm{~ms}^{-1}$ based on 164 samples. The result shows variation in mean wind speed in the Baltic Sea and the map may be useful as an estimate on offshore winds.

\section{On Wind Resource Mapping Using QuikSCAT Scatterometer}

Several scatterometers have been in orbit. The QuikSCAT mission is a quick recovery mission to fill the gap created by the loss of its predecessor. Since 1999 QuikSCAT has collected data. It provides microwave radar observations of the near-surface wind speed and direction under all weather and cloud conditions over Earth's oceans [29]. It is in sun-synchronous polar orbit of approximately $100 \mathrm{~min}$. With the swath width close to $17^{\circ}$ Earth degrees, this means that at the Equator two thirds of the Earth perimeter is covered during ascending passes, i.e., when the satellite travels from south to north, and similarly for descending passes. At higher latitudes this fraction is higher. Although called a polar orbit, the satellite does not come higher than to 81 degree latitude. The orbital path and swath combined provide approximately global coverage twice per day.

QuikSCAT raw data are processed by Remote Sensing Systems (http://www.ssmi.com), and the results are released as one file per day covering the Earth with a $0.25^{\circ}$ by $0.25^{\circ}$ resolution. For the higher latitudes with several satellite passes per day, the daily data files contain at any point the values of the last pass. There is close to two wind speed and direction sets per day for lower latitudes. There is exactly two for higher latitudes. QuikSCAT data are available from July 19, 1999 until October 2007, with only nine days missing. Fig. 10 shows the wind speed field from the ascending passes on September 24, 2004.

To test the reliability of the QuikSCAT data near a coast, QuikSCAT wind data from the nearest grid cell has been compared to meteorological mast data from Horns Rev (courtesy of DONG energy A/S), for the period June 1999 to December 2004, see Fig. 11. As the QuikSCAT data represents a kind of mean value over $0.25^{\circ}$ by $0.25^{\circ}$, which at Horns Rev is close to $15 \mathrm{~km}$ by $25 \mathrm{~km}$, the comparison is made to 1-hour averaged mast data (in one hour with a wind speed of $7 \mathrm{~ms}^{-1}$ the traversed 


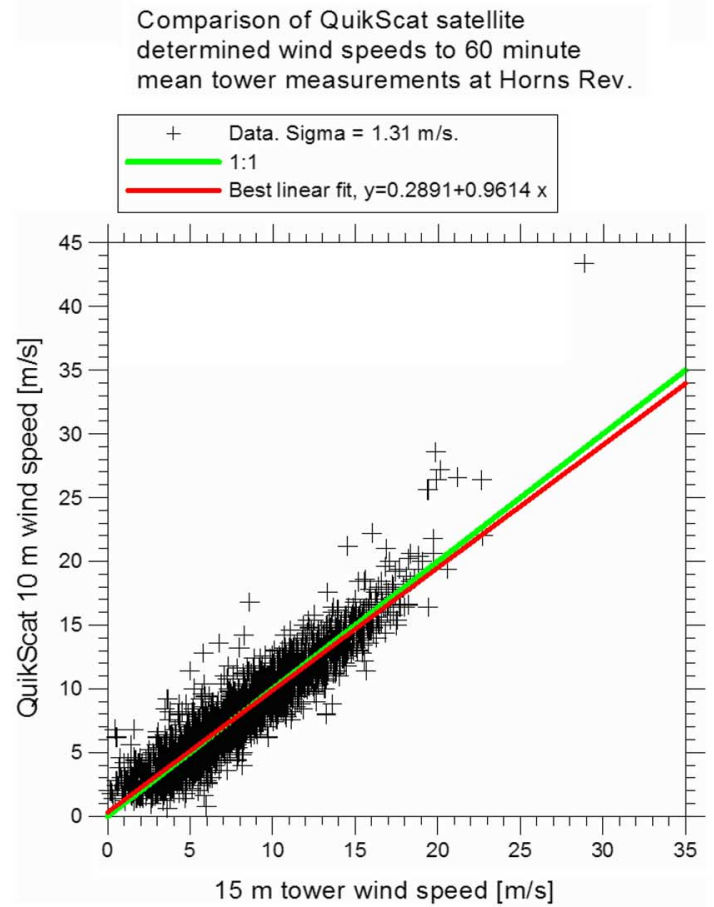

(a)

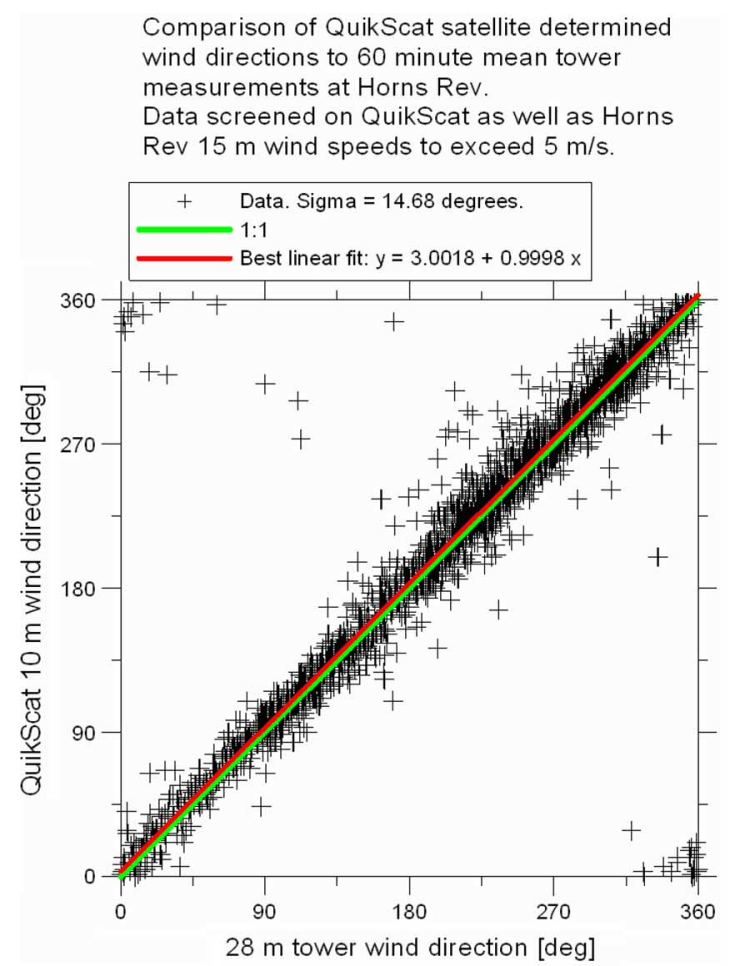

(b)

Fig. 11. Comparison between mast data and QuikSCAT data at Horns Rev in the North Sea for (top) wind speed and (bottom) wind direction.

length scale is $\sim 25 \mathrm{~km}$ ). The standard errors of the comparison results were found to be $\sim 1.3 \mathrm{~ms}^{-1}$ for wind speed and $\sim 15^{\circ}$ for wind direction.

From a wind resource point of view, however, it is more interesting to compare Weibull wind distribution parameters. Thus, wind observations based on a multiyear dataset of 10-min averages from the meteorological mast at Horns Rev are compared with the available QuikSCAT data for the same period. The mast data for the above mentioned period comprises $\sim 260000$ recordings against QuikSCAT's $\sim 3200$. The results found from QuikSCAT are mean wind speed of $8.04 \mathrm{~ms}^{-1}$ versus $8.13 \mathrm{~ms}^{-1}$ at mast, Weibull A $9.28 \mathrm{~ms}^{-1}$ versus $9.08 \mathrm{~ms}^{-1}$ at mast, and Weibull k 2.30 versus 2.29 at mast. The comparison result is shown in Fig. 12 as a function of 12 wind direction sectors and the equivalent wind roses are shown in Fig. 13. A high degree of correspondence between data is seen.

A drawback regarding wind resource estimation based on QuikSCAT is that the ascending and descending passes always fall within the same limited local time intervals, for which reason a systematic diurnal variation, where such would be of importance, is not measured. This problem could, however, to a wide extent be overcome by taking datasets from other satellites into the analysis.

\section{On Wind-Indexing Based on Passive Microwave SSM/I}

Ocean wind speed mapping from passive microwave SSM/I (Special Sensor Microwave/Imager) has been operational for $\sim 19$ years. The wind maps do not cover the coastal zone and only wind speed, not direction is retrieved. Thus, the application for wind resource estimation is limited. The data have, however, with exciting results been compared to the wind power production in Denmark.
At Remote Sensing Systems (http://www.ssmi.com) the $\mathrm{SSM} / \mathrm{I}$ wind data are accessible. The SSM/I geophysical dataset consists of data derived from observations collected by the SSM/I instruments carried onboard the Defense Meteorological Satellite Program (DMSP) series of polar orbiting satellites. These satellites are numbered as listed in Table I. There are gaps within the data.

Remote Sensing Systems performs a detailed processing of SSM/I data in two stages. The first stage produces an interim product which is made available in near real-time, generally within hours of data recording. This product can contain geo-location errors and erroneous brightness temperatures. The second stage is an offline quality checked wind product [39]. The difference between the two datasets was tested for a period without any noticeable differences; thus, it was concluded that in general the near real-time data are good.

The wind-index is defined as the produced wind power per year (or month) normalized with the long-term wind power production in percentage. For a normal year (or month) the windindex value is $100 \%$. For a windy year with winds above average, the wind-index is above $100 \%$. The wind-index is used for giving information on the expected wind energy production in a given period compared to long-term estimates. This is important when planning new wind farms-where local measurements typically only are available for a shorter period - as well as when checking the performance of existing wind farms. The normalization period used for the wind-index will influence results and, in general, the longer the time-series the better.

The SSM/I wind data have been analyzed. Wind data from two sites indicated in Fig. 14 were selected. Four data points at each site were selected to increase the number of useful observations. From the four wind speeds the average was taken. The 


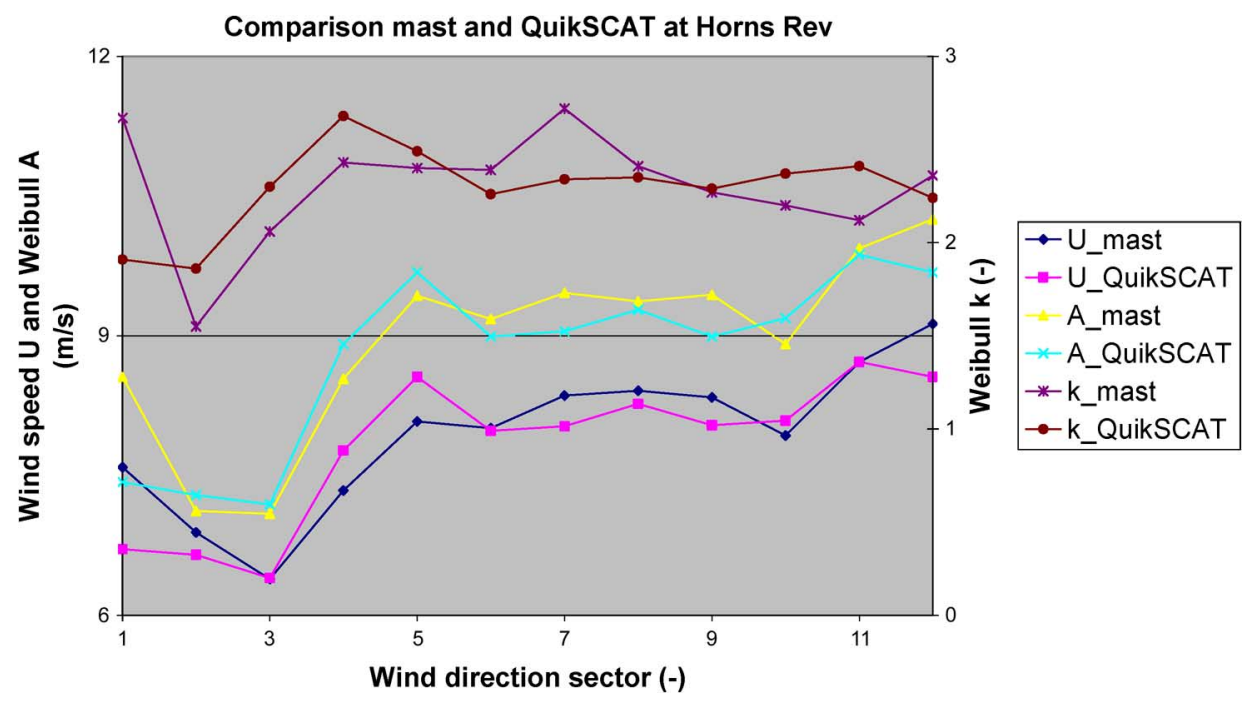

Fig. 12. Comparison of mean wind speed (U), Weibull A and Weibull $\mathrm{k}$ distribution parameters observed from meteorological mast and QuikSCAT for the period June 1999 to December 2004 at Horns Rev in the North Sea, Denmark, as a function of wind direction grouped into 12 30-degree direction bins clockwise (sector 1 is from $355^{\circ}$ to $015^{\circ}$ ). Courtesy of mast data: DONG energy A/S.

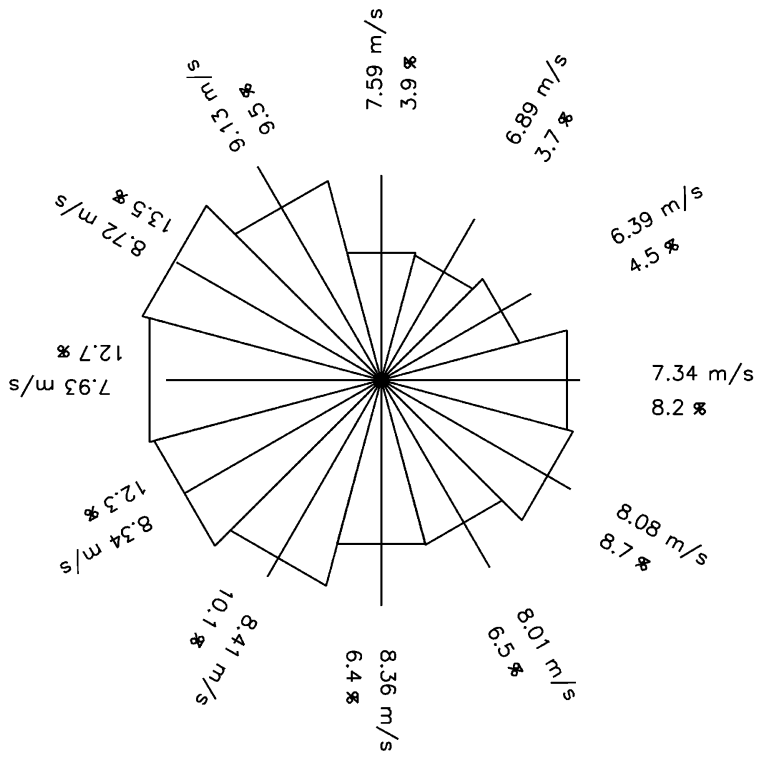

(a)

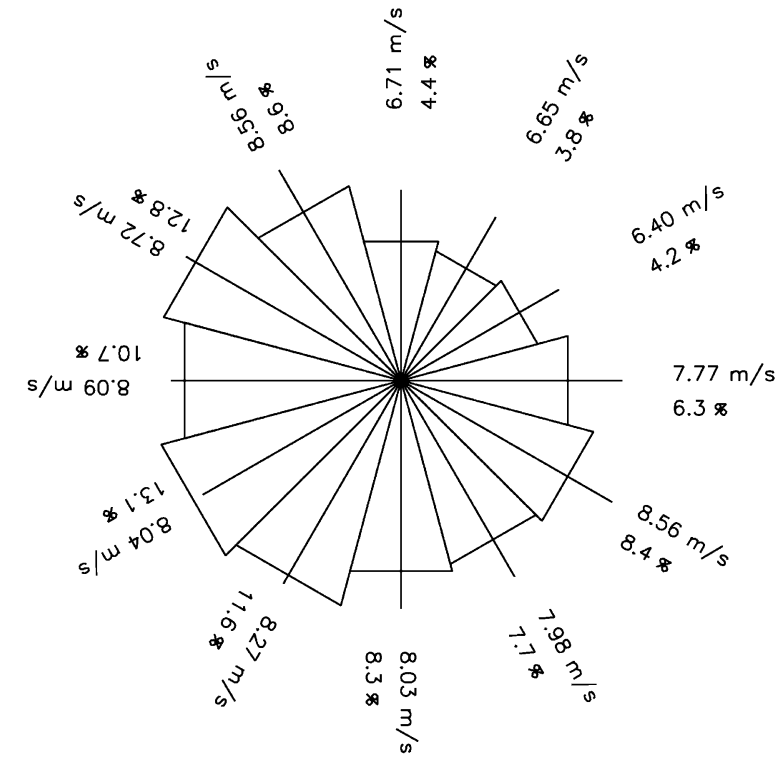

(b)

Fig. 13. Wind rose for Horns Rev based on (top) QuikSCAT (bottom) mast data.

TABLE I

SSM/I OPERATIONS

$\begin{array}{llll}\text { F08 SSM/I } & \text { Jul } 1987 & \text { to } & \text { Dec } 1991 \\ \text { F10 SSM/I } & \text { Dec } 1990 & \text { to } & \text { Nov } 1997 \\ \text { F11 SSM/I } & \text { Dec } 1991 & \text { to } & \text { May } 2000 \\ \text { F13 SSM/I } & \text { May 1995 } & \text { to } & \text { present } \\ \text { F14 SSM/I } & \text { May } 1997 & \text { to } & \text { present } \\ \text { F15 SSM/I } & \text { Dec } 1999 & \text { to } & \text { present }\end{array}$

data available from the period is shown in Fig. 15. From 1987 to 1990 , typically two data points per day were available. This increased to six points per day from around year 2000 to the present.

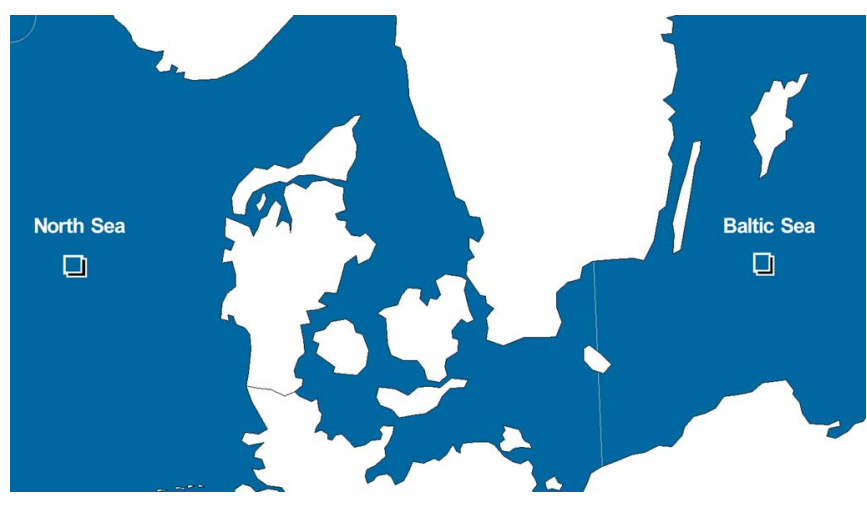

Fig. 14. Position in the North Sea and Baltic Sea within which four neighboring data points are extracted. 


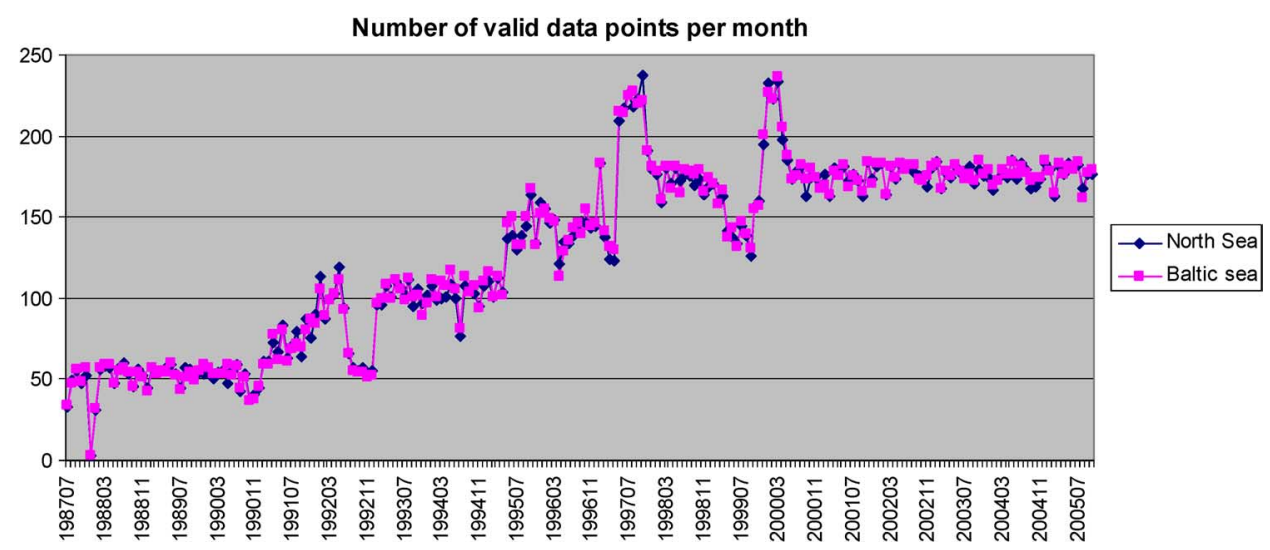

Fig. 15. Number of wind speed data from SSM/I from two sites in the Danish Seas.

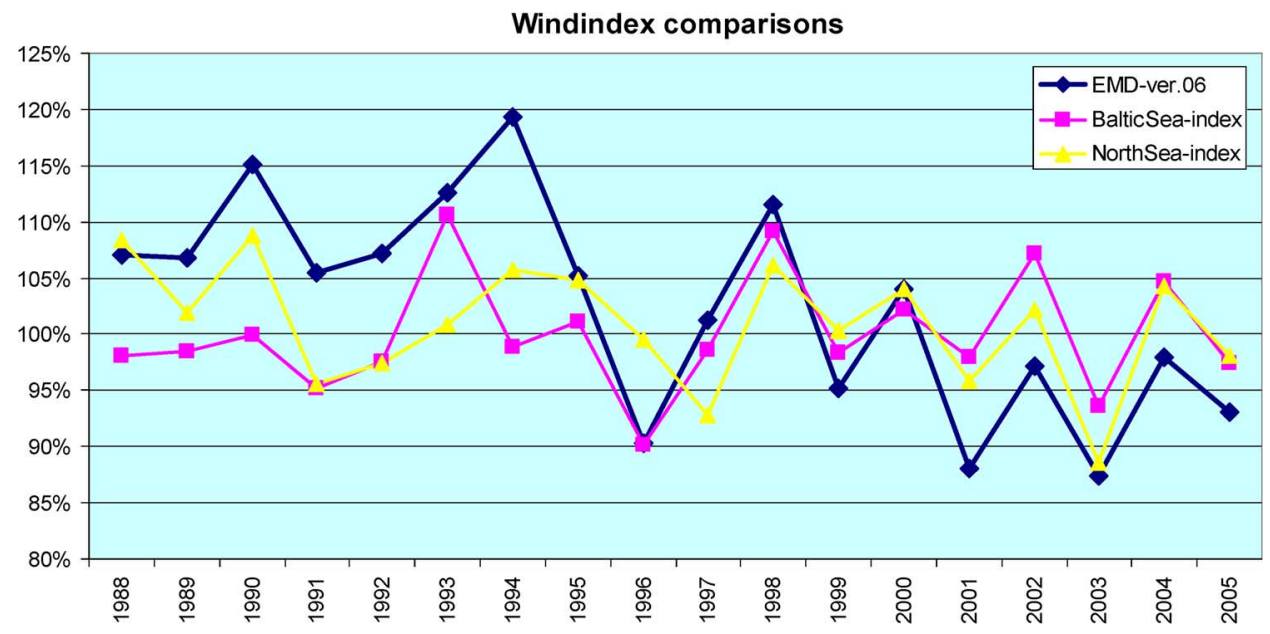

Fig. 16. Comparing the two SSM/I-based offshore wind-indexes with the Danish Wind Turbine Generator (WTG) based index calculated by EMD International A/S (ver.06).

The long-term average wind speeds based on all approved $\mathrm{SSM} / \mathrm{I}$ wind data for the 18 years investigated was found to be $7.7 \mathrm{~ms}^{-1}$ for the Baltic Sea and $8.3 \mathrm{~ms}^{-1}$ for the North Sea at $10 \mathrm{~m}$ AMSL. To get a wind-index relevant for offshore wind farming, the SSM/I wind data were extrapolated to $80 \mathrm{~m}$ as existing wind turbines operate at this height with an assumed logarithmic profile and a shear of 0.1 - this gives a scaling factor of 1.23. For each of the sites the wind-index was calculated based on squared wind speed (as wind turbine power curves are described by a parabola) with a "power curve limiter" at $15 \mathrm{~ms}^{-1}$, meaning that at wind speeds above $15 \mathrm{~ms}^{-1}$ the wind-index is set to $15^{2}$ (wind turbines operate at full capacity beyond this value). The result is shown in Fig. 16 jointly with the wind turbine generator (WTG) wind-index based on produced wind power in Denmark during the same period of time.

The first observation from Fig. 16 is that the decreasing trend in the EMD-ver.06 onshore WTG based index is not seen in the $\mathrm{SSM} / \mathrm{I}$ offshore wind indexes. A second observation is that there is correlation regarding years with low and high winds-especially from 1998 to 2005 . There appears to be a high correlation during recent years. This finding is important as in this period the onshore WTG index has a very high accuracy based on many large turbines. Before 1998 data sources were much weaker for the WTG index. The SSM/I data has six daily data points in recent years, and, therefore, the wind index is also of higher quality.

The interesting issue for offshore projects is if this finding truly can be used as a fact. In this case the offshore wind energy variation is much less than we see onshore and thereby the future offshore energy production expectation must be considered as $\sim 100 \%$ based on the last 5 years, where the onshore expectations are $\sim 7 \%$ below average [13].

\section{DISCUSSION AND CONCLUSION}

Remote sensing observations of winds in the atmospheric boundary layer from LiDAR and SoDAR have wide applications in wind energy. In particular, the technology is relevant for wind profile mapping across the rotor plane of large offshore wind turbines. The results appear to be of high accuracy when compared to offshore meteorological data. The data can also be used to study the structure of the atmospheric boundary layer. This is important as modeling of winds from lower heights to higher levels in the atmosphere frequently has to be done as observations often are taken at relatively low levels compared to large wind turbines. Thus, it is important to evaluate models describing the structure of the atmosphere using ground-based remote sensing observations. LiDAR and SoDAR have the great advantage of vertical profiling. 
In contrast, airborne and satellite observations of ocean winds have the advantage of spatial mapping in the horizontal domain. SAR images are, in particular, relevant for the offshore sites where detailed studies at the $1-\mathrm{km}$ scale are needed. The near real-time mapping of ocean winds from satellite SAR are being used in combination with software for wind resource statistics. For areas where a very quick estimate on the wind resources is needed, the series of QuikSCAT scatterometer wind maps may be useful. QuikSCAT is observing far offshore; thus, coastal winds may be different from ocean conditions. For the site Horns Rev in the North Sea, the comparison results appeared very good though.

The long-term trend in winds is not debated much compared to, e.g.,the public awareness on temperature and precipitation changes due to global warming. Yet in the wind industry it is clear that winds change significantly from year to year, as well as at longer time-scales. The lifetime of wind turbines is 20 years; thus, the cost and benefit of wind farming should be compared to this time-scale. The wind-index based on wind power production during two decades from the Danish wind turbine generators shows a remarkable good comparison to a wind-index based on passive microwave SSM/I ocean wind speed. The amplitude between windy and less windy years is smaller for the SSM/I-based wind-index than for the WTG-based wind-index. More importantly, the decreasing trend in the WTG-based wind-index is not found in the SSM/I based wind-index. In case this finding is truly describing offshore winds, it is good news for the offshore wind industry.

\section{ACKNOWLEDGMENT}

The authors would like to thank ESA EO-3644 for satellite images, DTU Space for the EMISAR airborne image, QuikSCAT and SSM/I data for the Remote Sensing Systems webpage, and DONG energy A/S for meteorological data from Horns Rev.

\section{REFERENCES}

[1] I. Antoniou, H. E. Jørgensen, T. Mikkelsen, S. Frandsen, R. Barthelmie, C. Perstrup, and M. Hurtig, "Offshore wind profile measurements from remote sensing instruments," presented at the EWEC, Athens, Greece, 2007 [Online]. Available: http://www.ewec2006proceedings.info/allfiles2/267_Ewec2006fullpaper.pdf

[2] J. R. Apel, "An improved model of the ocean surface-wave vector spectrum and its effects on radar backscatter," J. Geophys. Res. Ocean, vol. 99, pp. 16269-16291, 1994.

[3] R. J. Barthelmie and S. C. Pryor, "Can satellite sampling of offshore wind speeds realistically represent wind speed distributions," J. Appl. Meteorol., vol. 42, no. 1, pp. 83-94, 2003.

[4] R. C. Beal, G. S. Young, F. Monaldo, D. R. Thompson, N. S. Winstead, and C. A. Schott, High Resolution Wind Monitoring With Wide Swath SAR: A User's Guide. Washington, DC: U.S. Department of Commerce, 2005.

[5] M. B. Christiansen and C. B. Hasager, "Wake effects of large offshore wind farms identified from satellite SAR," Remote Sens. Environ., vol. 98, pp. 251-268, 2005.

[6] M. B. Christiansen and C. B. Hasager, "Using airborne and satellite SAR for wake mapping offshore," Wind Energy, vol. 9, pp. 437-455, 2006.

[7] M. B. Christiansen, W. Koch, J. Horstmann, and C. B. Hasager, "Wind resource assessment from C-band SAR," Remote Sens. Environ., vol. 105 , pp. 68-81, 2006.

[8] T. Elfouhaily, B. Chapron, K. Katsaros, and D. C. Vandemark, "A unified directional spectrum for long and short wind-driven waves," $J$. Geophys. Res.-Ocean, vol. 102, pp. 15781-15796, 1997.

[9] N. Fichaux and T. Ranchin, "Combined extraction of high spatial resolution wind speed and direction from SAR images: A new approach using wavelet transform," Canad. J. Remote Sens., vol. 28, no. 3, pp. 510-516, 2002.

[10] T. W. Gerling, "Structure of the surface wind field from the SEASAT SAR," J. Geophys. Res., vol. 91, no. C2, pp. 2308-2320, 1986.
[11] S. E. Gryning, E. Batchvarova, B. Brümer, H. E. Jørgensen, and S. E. Larsen, "On the extension of the wind profile over homogeneous terrain beyond the surface layer," Boundary-Layer Meteorol., vol. 124, pp. 251-268, 2007.

[12] K. Hansen, M. Courtney, P. Hummelshøj, P. Friis, and A. Knittel, "Validation of SODAR measurements for wind power assessment," presented at the Proc. EWEC, Athens, Greece, Feb. 27-Mar. 2, 2006 2007 [Online]. Available: http://www.ewec2006proceedings.info/allfiles2/0442_Ewec2006fullpaper.pdf

[13] C. B. Hasager, P. Astrup, M. Nielsen, M. B. Christiansen, J. Badger, P. Nielsen, P. B. Sørensen, R. J. Barthelmie, S. C. Pryor, and H. Bergström, SAT-WIND project Final Rep. Risø-R-1586(EN) Roskilde, Denmark, 2007, pp. 1-131 [Online]. Available: http://www.risoe.dk/rispubl/reports/ris-r-1586.pdf

[14] C. B. Hasager, R. J. Barthelmie, M. B. Christiansen, M. Nielsen, and S. C. Pryor, "Quantifying offshore wind resources from satellite wind maps: Study area the North Sea," Wind Energy, vol. 9, pp. 63-74, 2006.

[15] C. B. Hasager, E. Dellwik, M. Nielsen, and B. Furevik, "Validation of ERS-2 SAR offshore wind-speed maps in the North Sea," Int. J. Remote Sens., vol. 25, no. 19, pp. 3817-3841, 2004.

[16] C. B. Hasager, M. Nielsen, P. Astrup, R. J. Barthelmie, E. Dellwik, N. O. Jensen, B. H. Jørgensen, S. C. Pryor, O. Rathmann, and B. Furevik, "Offshore wind resource estimation from satellite SAR wind field maps," Wind Energy, vol. 8, pp. 403-419, 2005.

[17] C. B. Hasager, A. Peña, T. Mikkelsen, M. Courtney, I. Antoniou, S. E. Gryning, P. Hansen, and P. B. Sørensen, 12 MW Horns Rev Experiment Ris $\varnothing-\mathrm{R}-1506(\mathrm{EN})$ pp. 1-83. Roskilde, Denmark, 2007, [Online]. Available: http://www.risoe.dk/rispubl/reports/ris-r-1506.pdf.

[18] H. Hersbach, A. Stoffelen, and S. de Haan, "An improved C-band scatterometer ocean geophysical model function: CMOD5," J. Geophys. Res., vol. 112, 2007.

[19] J. Horstmann, S. Lehner, W. Koch, and R. Tonboe, "Computation of wind vectors over the ocean using spaceborne syntheric aperture radar," John Hopkins APL Tech. Dig., vol. 21, no. 1, pp. 100-107, 2000.

[20] J. Horstmann, H. Schiller, J. Schulz-Stellenfleth, and S. Lehner, "Global wind speed retrieval from SAR," IEEE Trans. Geosci. Remote Sens., vol. 41, no. 10, pp. 2277-8622, Oct. 2003.

[21] W. Koch, "Directional analysis of SAR images aiming at wind direction," IEEE Trans. Geosci. Remote Sens., vol. 42, no. 4, pp. 702-710, Apr. 2004.

[22] H. Masuko, K. Okamoto, M. Shimada, and S. Niwa, "Measurement of microwave backscattering signatures of the ocean surface using X-band and Ka-band airborne scatterometers," J. Geophys. Res., vol. 91 C11, no. 13, pp. 13065-13083, 1986.

[23] F. Monaldo, V. Kerbaol, P. Clemente-Colón, B. Furevik, J. Horstmann, J. Johannessen, X. Li, W. Pichel, T. D. Sikora, D. J. Thomson, and C. Wackerman, "The SAR measurement of ocean surface winds: An overview," presented at the Proc. 2nd Workshop Coastal and Marine Applications of SAR, Svalbard, Norway, 2003, unpublished.

[24] F. Monaldo, D. R. Thompson, W. Pichel, and P. Clemente-Colón, "A systematic comparison of QuickSCAT and SAR ocean surface wind speeds," IEEE Trans. Geosci. Remote Sens., vol. 42, no. 2, pp. 283-291, Feb. 2004.

[25] F. Monaldo, D. R. Thompson, N. S. Winstead, W. Pichel, P. ClementeColón, and M. B. Christiansen, "Ocean wind field mapping from synthetic aperture radar and its application to research and applied problems," Johns Hopkins Apl. Tech. Dig., vol. 26, pp. 102-113, 2005.

[26] F. M. Monaldo, D. R. Thompson, R. C. Beal, W. G. Pichel, and P. Clemente-Colón, "Comparison of SAR-derived wind speed with model predictions and ocean byou measurements," IEEE Trans. Geosci. Remote Sens., vol. 39, no. 12, pp. 2587-2600, Dec. 2001.

[27] N. Mortensen, D. N. Heathfield, L. Landberg, O. Rathmann, I. Troen, and E. L. Petersen, Wind Atlas Analysis and Wind Atlas Analysis and Application Program: WAsP 7.0 Help Facility pp. 1-277, Risø National Lab. Roskilde, Denmark, 2000.

[28] A. A. Mouche, D. Hauser, J. F. Daloze, and C. Guerin, "Dual-polarization measurements at C-band over the ocean: Results from airborne radar observations and comparison with ENVISAT ASAR data," IEEE Trans. Geosci. Remote Sens., vol. 43, no. 4, pp. 753-769, Apr. 2005.

[29] NASA, NASA Quick Scatterometer, QuikSCAT Science Data Product, User's Manual, Overview and Geophysical Data Products, Jet Propulsion Lab., California Inst. Technol., Pasadena, 2001.

[30] M. Nielsen, P. Astrup, C. B. Hasager, R. J. Barthelmie, and S. C. Pryor, Satellite Information for Wind Energy Applications pp. 1-57, Risø National Lab., Risø-R-1479(EN). Roskilde, Denmark, 2004, [Online]. Available: http://www.risoe.dk/rispubl/VEA/veapdf/ris-r-1479.pdf.

[31] A. Peña, C. B. Hasager, S. E. Gryning, M. Courtney, I. Antoniou, and T. Mikkelsen, "Offshore wind profiling using light detectinon and ranging measurements," Wind Energy, 2008, in press.

[32] S. C. Pryor, M. Nielsen, R. J. Barthelmie, and J. Mann, "Can satellite sampling of offshore wind speeds realistically represent wind speed distributions? Part II quantifying uncertainties associated with sampling strategy and distribution fitting methods," J. Appl. Meteorol., vol. 43, pp. 739-750, 2004. 
[33] R. Romeiser, W. Alpers, and V. Wismann, "An improved composite model for radar backscattering cross section of the ocean surface; 1 . Theory and model optimization/validation by scatterometer data," $J$. Geophys. Res., vol. 102 C11, no. 25, pp. 25237-25250, 1997.

[34] W. Sass, The Technology of the 200-Metre Met Mast pp. 27-29, 2007.

[35] D. A. Smith, M. Harris, A. S. Coffey, T. Mikkelsen, H. E. Jørgensen, J. Mann, and G. Danielian, "Wind lidar evaluation at the Danish wind test site in Høvsøre," Wind Energy, vol. 9, pp. 87-93, 2007.

[36] A. Stoffelen and D. L. T. Anderson, "Scatterometer data interpretation: Estimation and validation of the transfer fuction CMOD4," J. Geophys. Res., vol. 102, no. C3, pp. 5767-5780, 1997.

[37] I. Troen and E. L. Petersen, European Wind Atlas Risø National Lab. Roskilde, Denmark, 1989, 656 pp.

[38] F. van Hulle, Wind Power in Europe: Trends and Challenges 2007.

[39] F. J. Wentz, "A well calibrated ocean algorithm for SSM/I," J. Geophys. Res., vol. 102, no. C4, pp. 8703-8718, 1997.

[40] G. S. Young, T. D. Sikora, and N. S. Winstead, "Manual and semiautomated wind direction editing for use in the generation of synthetic apeture radar wind speed imagery," J. Appl. Meteor. Climatol., vol. 46, pp. 776-790, 2007.

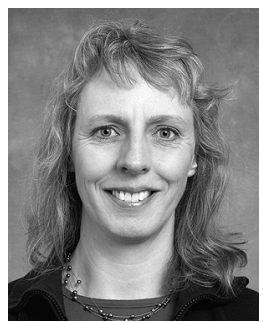

Charlotte Bay Hasager received the M.Sc. and Ph.D. degrees from the University of Copenhagen, Denmark, in 1992 and 1996, respectively.

She is currently a Senior Scientist at the Ris $\varnothing$ National Laboratory for Sustainable Energy, Denmark Technical University, in the Wind Energy Department. She is specialized in satellite remote sensing, micrometeorology, and wind energy.

Dr. Hasager is currently President of the Atmospheric Sciences Division, European Geosciences Union, and a member of the steering committee of the Danish Space Consortium.

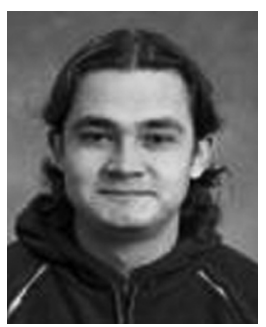

Alfredo Peña received the M.Sc. degree from the University of Oldenburg, Germany, and the M.Sc. degree from the University of Los Andes, Colombia. $\mathrm{He}$ is currently pursuing the Ph.D. degree at the Ris $\varnothing$ National Laboratory for Sustainable Energy, Denmark Technical University, in the Wind Energy Department.

$\mathrm{He}$ is specialized in offshore wind, ground-based remote sensing, and wind energy.

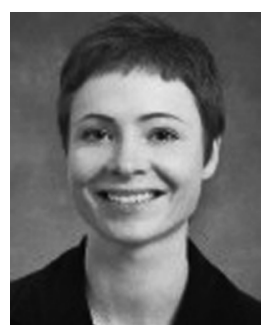

Merete Bruun Christiansen received the M.Sc. and Ph.D. degrees from the University of Copenhagen, Denmark, in 2002 and 2006, respectively.

She is currently a Scientist at the Risø National Laboratory for Sustainable Energy, Denmark Technical University, in the Wind Energy Department. She is specialized in satellite remote sensing, micrometeorology, and wind energy.

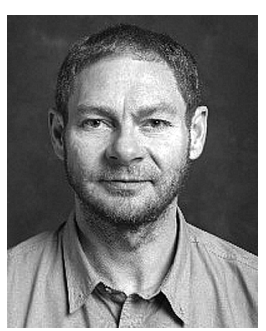

Poul Astrup received the Ph.D. degree from Denmark Technical University (DTU).

$\mathrm{He}$ is currently a Scientific Specialist at the Ris $\varnothing$ National Laboratory for Sustainable Energy, DTU, in the Wind Energy Department. He is specialized in air pollution, meteorological modeling, programming, and wind and satellite data.

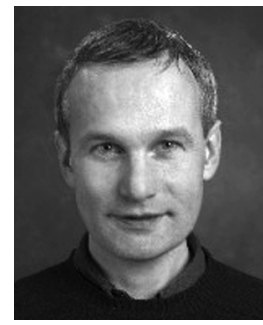

Morten Nielsen received the Ph.D. degree from Denmark Technical University (DTU).

$\mathrm{He}$ is currently a Senior Scientist at the Risø National Laboratory for Sustainable Energy, DTU, in the Wind Energy Department. He is specialized in heavy gas dispersion, micrometeorology, turbulence, wind energy, and satellite remote sensing.

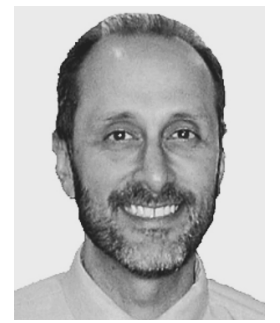

Frank Monaldo received the B.A. and M.S. degrees from the Catholic University of America, Washington, DC, in 1977 and 1978, respectively.

$\mathrm{He}$ is presently a Principal Staff Physicist at the Johns Hopkins University Applied Physics Laboratory, Laurel, MD. He has focused on the scientific use of remotely sensed data from both passive and active sensors, to measure geophysical properties of the ocean and atmosphere. He serves on the Alaska SAR Facility User Working Group.

Mr. Monaldo is member of the American Geophysical Union, the URSI Commission F, Sigma Xi, and the American Meteorological Society.

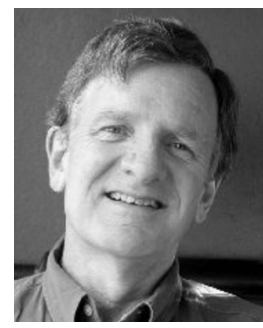

Donald Thompson began his career studying problems in few-body nuclear reactions and stellar nucleosynthesis at the California Institute of Technology, the University of Minnesota, and the Universität Tübingen, Tübingen, Germany. Since 1980, he has been with The Johns Hopkins University, Applied Physics Laboratory, Laurel, MD, where he is currently supervisor of the Theory and Modeling Section of the Ocean Remote Sensing Group. For the past 25 years, he has participated in programs involving oceanographic measurements, numerical modeling of surface wave phenomena, electromagnetic backscatter calculations, and SAR image simulation. He served as modeling leader for the ONR High-Res ARI and was PI on numerous other ONR, NASA, and NOAA grants. He is currently PI on a National Ocean Partnership Program (NOPP) grant related to hurricane wind mapping using SAR and a NOAA grant concerned with geophysical parameter retrieval from microwave sensing systems using polarization diversity. During the past four years, he has begun collaborating with scientists at the Risø National Laboratory for Sustainable Energy, Roskilde, Denmark, concerning the remote sensing of near-surface ocean wind fields to aid in the placement of wind farms. He teaches electrodynamics in the Whiting School of Engineering, Johns Hopkins University, and is an Adjunct Professor in the Rosenstiel School for Marine and Atmospheric Sciences, University of Miami, Miami, FL.

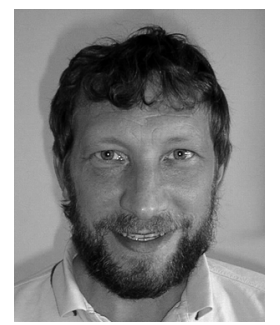

Per Nielsen is the Director of EMD International, Denmark. EMD is a software and consultancy company supplying countries worldwide with software and consultancy services within the field of project design, planning, and documentation of environmental friendly energy projects, particularly wind energy projects. 